\title{
Vascular liver lesions: contemporary views on long-recognized entities
}

\author{
Christine Sempoux ${ }^{1}$ (i) $\cdot$ Paulette Bioulac-Sage ${ }^{2}$ (i)
}

Received: 22 February 2018 / Accepted: 23 February 2018 / Published online: 14 March 2018

(C) Springer-Verlag GmbH Germany, part of Springer Nature 2018

In this issue of the Archives, you will discover a miniseries devoted to vascular liver diseases. In this field, nomenclature has largely evolved, taking advantage of a better understanding of the pathogenesis and clinical manifestations of these diseases. New histological features have also been identified, helping the pathologists who have to examine liver biopsies or surgical specimens to reach an accurate and helpful diagnosis. The four reviews summarize the current knowledge and highlight the contemporary concepts in this matter, as they have been presented and discussed in September 2016 in a symposium on "Dynamic pathology of liver tissue due to vascular changes and pathologic liver perfusion" organized by $\mathrm{V}$ Paradis, secretary of the Working Group of Digestive Diseases, during the 28th European Congress of the European Society of Pathology held in Köln, Germany.

The first review of the series is an extensive and comprehensive description of vascular liver diseases from the clinical side by one of the main expert in the field, D Valla, who has been deciphering the problem for years. Sharing his large experience, he has always a hint to pathology and at how we can be helpful in the management of the patients. This is emphasized by the great dialog within this review with the pathologist, D Cazals, who was his correspondent behind the microscope [1]. They describe together the new understanding of vascular disorders of the liver, with their

This editorial is part of the Topical Collection on Vascular liver lesions: contemporary views on long-recognized entities

Christine Sempoux

christine.sempoux@chuv.ch

1 Service of Clinical Pathology, Lausanne University Hospital, Institute of Pathology, 25 rue du Bugnon,

1011 Lausanne, Switzerland

2 Inserm, UMR1053 Bordeaux Research in Translational Oncology, BaRITOn, F-33000 Bordeaux, Université de Bordeaux, 33076 Bordeaux, France pathophysiology and new denominations, and they mention the progresses relevant to the clinical aspects, with indications to the need for liver biopsies when helpful.

The second review discusses the new concept of regressing cirrhosis. The two authors, P Hytiroglou and $\mathrm{N}$ Theise, are well-known for their engaged work in making liver pathology more precise and comprehensive. They are part of the group of pathologists who suggested abandoning the term cirrhosis [2], and they are both dealing in their every day practice with difficulties in medical liver. Cirrhosis has been considered to correspond to the end stage of chronic liver diseases for a long time. Now, we do recognize that hepatic architecture is under constant remodeling, mainly related to vascular abnormalities. The histologic changes may be progressing or regressing, depending on alternative injuries and repairs, and regression of cirrhosis has been demonstrated in various chronic liver diseases. After retracing the story of the first paper on this subject by I Wanless published 18 years ago, with all the turmoil created by this new challenging concept, the authors provide the detailed descriptive criteria for diagnosing the regression features, with excellent illustrations helping us to implement its recognition in our practice.

The third paper, written by M Guido et al., covers the topic of idiopathic non cirrhotic portal hypertension (ICPNH), an old problem that has shown significant changes in its understanding during the last years and needed such a comprehensive review and synthesis, by an author who has always been interested in the subject [3]. The histological description is the perfect example of a didactic and detailed explanation that will be useful for pathologists who interpret liver biopsies every day. The review is also important for more general pathologists who should be exposed from time to time to these almost normal-looking liver biopsies, only showing subtle changes that are the clues to explain the hypertension, or even preclude its development and are already responsible for abnormal liver function tests. This is indeed an under-recognized vascular liver disease in which liver biopsy is an essential tool that allows the identification of the characteristic lesions precisely described and beautifully illustrated in this review. 
The last paper was prepared by the authors of this editorial, joined by V Paradis, who organized the symposium, and by $\mathrm{C}$ Balabaud, hepatologist, who has always been close to pathology, providing his important clinical input. Together, we reviewed our experience with the liver nodules that are developing in the context of vascular liver diseases [4]. For these nodules, mostly studied and described by our colleagues in radiology, a general synthesis, more comprehensive on a pathological point of view, was missing. Therefore, we detail the histological criteria allowing a differential diagnosis and we present a summary of available data on what has been described in each single vascular liver disease in the literature. In this specific context, precise diagnosis of the type of nodules and management of the patients are also more complex, a point that we discuss at the end of the review.

We do hope that you will enjoy reading this miniseries on vascular liver lesions, in which we aimed to share comprehensively the contemporary views on long-recognized entity, as much as we have been pleased to build it together, and that we succeed in our attempt to help you in your routine practice.

\section{Compliance with ethical standards}

Conflict of interest The authors declare that they have no conflicts of interest.

\section{References}

1. Cazals-Hatem D, Hillaire S, Rudler M, Plessier A, Paradis V, Condat B, Francoz C, Denninger MH, Durand F, Bedossa P, Valla DC (2011) Obliterative portal venopathy: portal hypertension is not always present at diagnosis. J Hepatol 54:455-461

2. Hytiroglou P, Snover DC, Alves V, Balabaud C, Bhathal PS, BioulacSage P, Crawford JM, Dhillon AP, Ferrell L, Guido M, Nakanuma Y, Paradis V, Quaglia A, Theise ND, Thung SN, Tsui WM, van Leeuwen DJ (2012) Beyond "cirrhosis": a proposal from the International Liver Pathology Study Group. Am J Clin Pathol 137:5-9

3. Guido $\mathrm{M}$, Sarcognato $\mathrm{S}$, Sonzogni A, Lucà MG, Senzolo M, Fagiuoli S, Ferrarese A, Pizzi M, Giacomelli L, Colloredo G (2016) Obliterative portal venopathy without portal hypertension: an underestimated condition. Liver Int 36:454-460

4. Sempoux C, Paradis V, Komuta M, Wee A, Calderaro J, Balabaud C, Quaglia A, Bioulac-Sage P (2015) Hepatocellular nodules expressing markers of hepatocellular adenomas in Budd-Chiari syndrome and other rare hepatic vascular disorders. J Hepatol 63:1173-1180 